\title{
The estimation of design rainfalls for South Africa using a regional scale invariant approach"
}

\author{
JC Smithers* and RE Schulze \\ School of Bioresources Engineering and Environmental Hydrology, University of KwaZulu-Natal, Pietermaritzburg \\ Private Bag X01, Scottsville 3209, South Africa
}

\begin{abstract}
Accurate estimates of design rainfall are essential inputs in water resource planning and engineering design. The duration of design rainfall which is required for design flood estimation may range from as short as 5 min for small urban catchments which have a rapid hydrological response, to a few days for large regional scale flood studies. In South Africa, as in many countries, the spatial density and record lengths of rainfall measured manually at daily intervals is far greater than rainfall recorded continuously. However, continuously recorded rainfall is needed to estimate design rainfall for durations shorter than $24 \mathrm{~h}$. In this study, the scaling characteristics of extreme rainfall and a regional approach, based largely on the more reliable and abundant daily rainfall data, are utilised to estimate design rainfalls in South Africa for durations ranging from 5 min to $7 \mathrm{~d}$.
\end{abstract}

Keywords: design rainfall, South Africa, regionalisation, scaling, extreme rainfall, rainfall probability

\section{Introduction}

The estimation of design flood events is necessary for the planning and design of engineering projects (Rahman et al., 1998). Hence, flood-frequency analysis remains a subject of great importance as a result of the economic and environmental impacts of failures of hydraulic structures (Pilgrim and Cordery, 1993; Bobee and Rasmussen, 1995). However, reliable estimates of flood frequency in terms of peak flows and volumes remain a current challenge in hydrology (Cameron et al., 1999). Cordery and Pilgrim (2000) express the opinion that the demands for improved estimates of floods have not been met with any increased understanding of the fundamental hydrological processes.

Standard techniques for flood estimation have been developed for many countries. These generally include statistical analyses of observed peak discharges, where these are available, and event modelling using rainfall-runoff techniques. Observed streamflow data are often not available at the site of interest and rainfall eventbased methods frequently have to be used. This requires a probabilistically based estimate of rainfall, generally referred to as design rainfall, to be made at the site of interest. The frequently used term "design rainfall” thus comprises the rainfall depth and duration, or intensity, associated withh a given probability of exceedance which, in turn, is inversely related to the commonly used term, return period. Design rainfall depths for various durations are thus required for the many engineering and conservation design decisions made annually in South Africa and which result in many millions of Rand of construction each year. For example, engineers and hydrologists involved in the design of hydraulic structures (e.g. culverts, bridges, dam spillways and reticulation for drainage systems) need to assess

\footnotetext{
\# This paper was originally presented at the 2003 SANCIAHS

Conference, 3-5 September 2003, Port Elizabeth, South Africa.

* To whom all correspondence should be addressed.

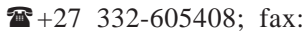

e-mail:smithers@ukzn.ac.za

Received 19 April 2004; accepted in revised form 10 August 2004.
}

the frequency and magnitude of extreme rainfall events in order to generate design flood hydrographs. Hence, depth-duration-frequency (DDF) relationships, which utilise recorded events in order to predict future exceedance probabilities and thus quantify risk and maximise design efficiencies, are a key concept in the design of hydraulic structures (Schulze, 1984).

Numerous regional and national scale studies in South Africa have focused on estimating design rainfalls for durations $d \leq 24 \mathrm{~h}$. These include those of Vorster (1945), Woolley (1947), SAWB (1956), Reich (1961), Reich (1963), Bergman and Smith (1973), SAWB (1974), Adamson (1977), Alexander (1978), Midgley and Pitman (1978), Van Heerden (1978), Henderson-Sellers (1980), Schulze (1980), Adamson (1981), Sinske (1982), Op Ten Noort (1983), Schulze (1984), Weddepohl et al. (1987), Weddepohl (1988), Smithers (1996), Smithers and Schulze (2000a) and Alexander (2001). Studies in South Africa which have estimated design rainfalls for durations of $1 \mathrm{~d}$ and longer include those by SAWB (1956), Schulze (1980), Adamson (1981), Pegram and Adamson (1988) and Smithers and Schulze (2000b). With the exception of the research by Smithers and Schulze (2000a; 2000b), the other studies have all utilised point design rainfall values using at-site data only and no regionalisation was performed in an attempt to increase the reliability of the design values at gauged sites and for the estimation of design values at un-gauged sites.

Smithers and Schulze(2000a) utilised digitised rainfall data from 172 sites in South Africa, each of which had at least 10 years of record, to estimate short-duration design rainfall. As illustrated by Smithers (1993) and Smithers and Schulze (2000a), many of the digitised rainfall data must be viewed as unreliable as many errors in the digitisation process are evident in the data. In addition, comparisons between the $24 \mathrm{~h}$ rainfall totals, computed from the digitised rainfall data, and daily rainfall, as measured at 08:00 every day using standard non-recording rain gauges at the same site, indicated numerous significant discrepancies in the two values. Data from 1806 rainfall stations in South Africa which have at least 40 years of quality controlled daily records were utilised by Smithers and Schulze(2000b) to estimate design rainfalls for 1 to 7 d durations 
in South Africa.

The approach developed by Smithers and Schulze (2003) to overcome the deficiencies in the digitised rainfall data is to utilise, as far as possible, the more abundant and reliable daily rainfall data which generally have longer record lengths than the digitised rainfall data. The objective of this paper is to briefly outline the regional, scale invariant approach developed by Smithers and Schulze (2003) and to illustrate the software developed to estimate design rainfalls at any location in South Africa for durations ranging from $5 \mathrm{~min}$ to $7 \mathrm{~d}$ and for return periods ranging from 2 to 200 years.

\section{Regional approach to design rainfall estimation}

The regional approach to design rainfall estimation developed by Smithers and Schulze (2000a; 2000b) utilises an approach proposed by Hosking and Wallis (1993; 1997), which is based on L-moments. An index storm approach assumes that within a homogeneous region the frequency distribution of observations from all the sites in the region are identical, apart from a site-specific scaling factor. Assuming that $N$ sites form a homogeneous cluster, with site $i$ having a record length $n_{i}$, sample mean $l_{1}^{(i)}$ and sample L-moment ratios $t^{(i)}$, $t_{3}^{(i)}, t_{4}^{(i)}$, then the regional average L-moment ratios $t^{R}, t_{3}{ }^{R}, t_{4}{ }^{R}$, which are weighted in proportion to the sites' record lengths, are computed as:

$$
\begin{aligned}
& t^{R}=\sum_{i=1}^{N} n_{i} t^{(i)} / \sum_{i=1}^{N} n_{i} \\
& t_{r}^{R}=\sum_{i=1}^{N} n_{i} t_{r}^{(i)} / \sum_{i=1}^{N} n_{i}, r=3,4, \ldots . .
\end{aligned}
$$

The regional average mean is set to 1 (i.e. $l_{1}^{(R)}=1$ ) and the selected distribution is fitted by equating the theoretical L-moment ratios to $l_{1}^{(R)}, t^{R}, t_{3}{ }^{R}, t_{4}{ }^{R}$ calculated in Eqs. (1) and (2). As shown in Eq. (3), the quantile, with non-exceedance probability $F$, may be estimated by combining the quantile function of the fitted distribution $(\stackrel{\wedge}{)}$, commonly referred to as a growth curve, with the at-site mean.

$$
\hat{Q}_{i}(F)=l_{1}^{(i)} \hat{q}(F)
$$

Growth curves thus represent the relationship between design rainfall, scaled by an index value, and event duration. Smithers and Schulze (2003) noted that there are inconsistencies in the $24 \mathrm{~h}$ growth curves developed independently using the digitised and daily rainfall databases compiled by Smithers and Schulze (2000a; 2000b) respectively. However, they illustrated that there should be no systematic differences between higher order L-moment ratios for Annual Maximum Series (AMS) extracted using a fixed window (from daily data) and a sliding window (from digitised data). It was also established that the $24 \mathrm{~h}$ growth curve, derived from digitised data using a sliding $24 \mathrm{~h}$ window, and the $1 \mathrm{~d}$ growth curve derived from daily rainfall data, should be the same. The differences in the short and long duration growth curves were attributed largely to the non-concurrent periods and different length of records used in the analyses and, to a lesser extent, to the errors in the digitised rainfall data.

\section{Scaling of L-moment ratios and growth curves}

Smithers and Schulze (2000a) developed growth curves for 15 relatively homogeneous regions in South Africa using digitised rainfall data while Smithers and Schulze (2000b) developed growth curves for 78 relatively homogeneous regions in South Africa using daily rainfall data. The regional L-moment ratios computed from the digitised rainfall data for the 15 short-duration clusters developed by Smithers and Schulze (2000a) using digitised rainfall data are shown in Fig. 1. Generally, scale invariance of the L-Coefficient of Variation (L-CV) is a characteristic displayed in most clusters for durations ranging from as short as $10 \mathrm{~min}$ to $4 \mathrm{~d}$, although there are some exceptions to this trend (Clusters 2, 3, 7 and 8). More deviation from scale invariance was evident and expected for L-skewness. It is noted that the trends in L-CV and L-skewness for durations shorter and longer than $24 \mathrm{~h}$ were similar and no distinct shifts in L-CV and L-skewness are evident between 24 and $48 \mathrm{~h}$ durations.

The regional average L-moment ratios, computed from the daily rainfall data by Smithers and Schulze (2000b), for selected long duration clusters are shown in Fig. 2. From these examples it is evident that scale invariance of both L-CV and L-skewness with duration is a characteristic of daily rainfall for durations ranging from 1 to $7 \mathrm{~d}$ in a range of climatic regimes. Deviations from scale invariance for L-CV and L-skewness are postulated for both the digitised and daily rainfall data to be the result of either one, or a combination of, sampling variability, some heterogeneity within a cluster and missing periods of data.

The degree of scale invariance within the digitised and daily rainfall databases is illustrated by computing the slope of the relationship between the regional L-moment ratios and duration for each cluster and for both databases. Durations ranging from $5 \mathrm{~min}$ to $24 \mathrm{~h}$ were used in calculating the slope for the 15 short-duration clusters and from 1 to $7 \mathrm{~d}$ for the 78 long duration clusters. A frequency analysis of the 15 and 78 slopes for the second (L-CV) and third (L-skewness) regional L-moment ratios was performed and the results are shown in Fig. 3.

A hypothesis of scale invariance assumes that the slope should be zero. The mean of the slopes of the relationship between the regional L-moment ratios and duration for durations of 5 min to 24 $\mathrm{h}$ and for 1 to $7 \mathrm{~d}$ computed for the short- and long-duration clusters respectively, are not significantly different from zero. Hence, it is postulated that the variation in the slopes displayed in Fig. 3 are the result of a combination of sampling variability, some heterogeneity within the clusters and periods of missing data.

\section{Sampling variability of extreme rainfall data}

The sampling variability of the annual maximum rainfall series was estimated by Smithers and Schulze (2003) using three approaches. The first considered sliding windows of data extracted from windows from the entire period of record, the second utilised stochastic modelling of the rainfall process and the third approach implemented a bootstrapping technique. In this paper, only selected results from the bootstrapping technique are presented.

The bootstrapping algorithm described by Adamson et al. (1984) and Zucchini and Adamson (1989) was utilised to estimate the sampling variability of the L-moment ratios and hence the errors in the growth curves, based on the assumption of scale invariance. One thousand random samples extracted from the annual maximum series were used to estimate the $90 \%$ confidence intervals. These are illustrated in Fig. 4 for rain gauge N23, located in the Ntabamhlope Research Catchments near Estcourt in the KwaZulu-Natal midlands. As expected, and evident in Fig. 4, the mean of the 1000 bootstrapped samples (bs) correlates well with the mean of the annual maximum series extracted from the observed data (obs). In addition, at rain gauge $\mathrm{N} 23$, both the $24 \mathrm{~h} \mathrm{L-CV}$ and $24 \mathrm{hL}$-skewness fall within the $90 \%$ confidence interval for durations ranging from 10 min to $7 \mathrm{~d}$. Hence, the $24 \mathrm{~h}$ growth factors also generally fall within the $90 \%$ growth factor confidence intervals for a wide range of durations, as shown for the 2 and 50 year return period rainfalls in 
Cluster 1
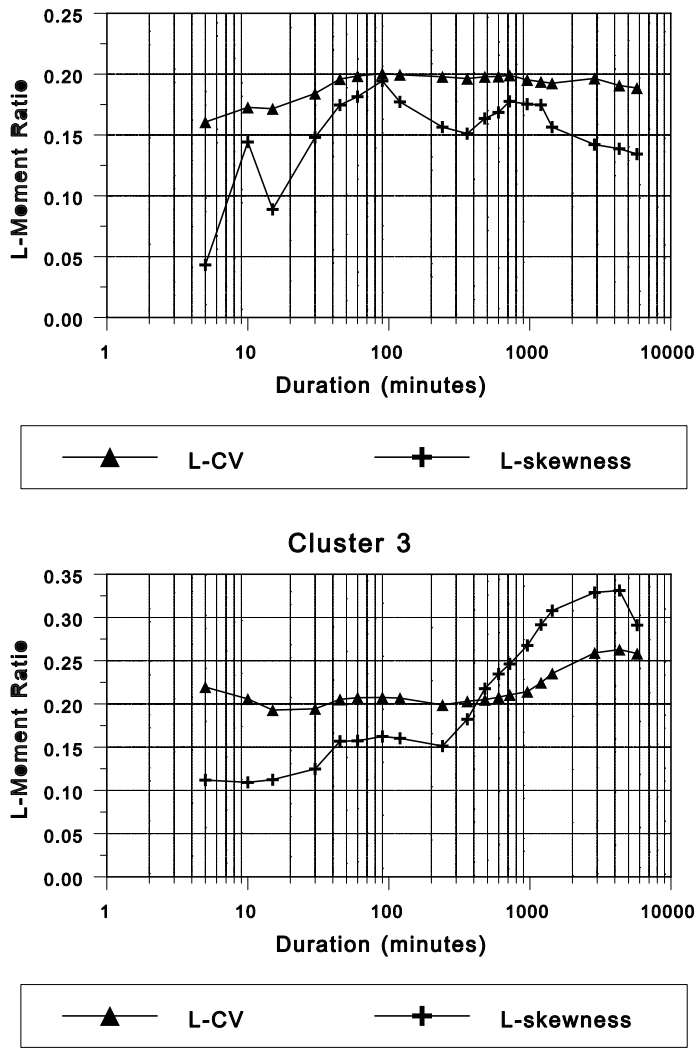

Cluster 5
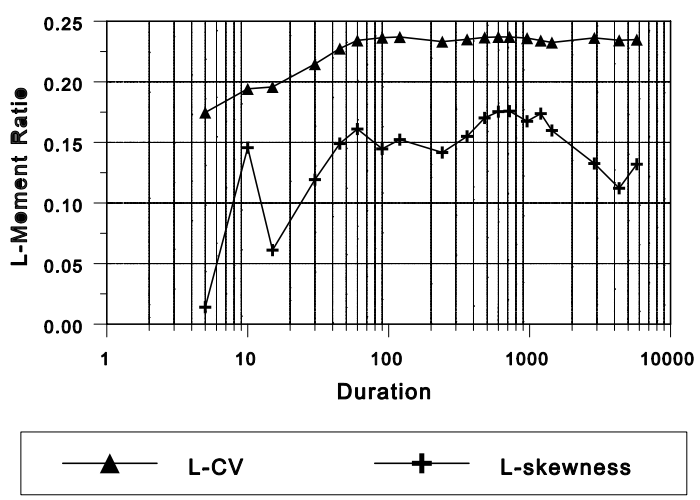

Cluster 7
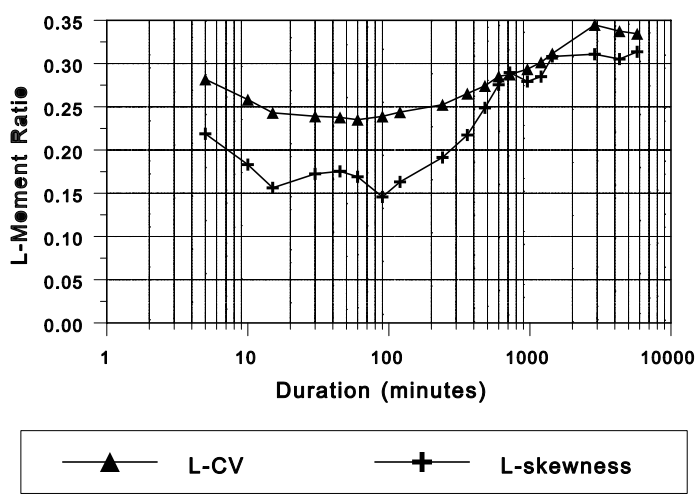

Cluster 2
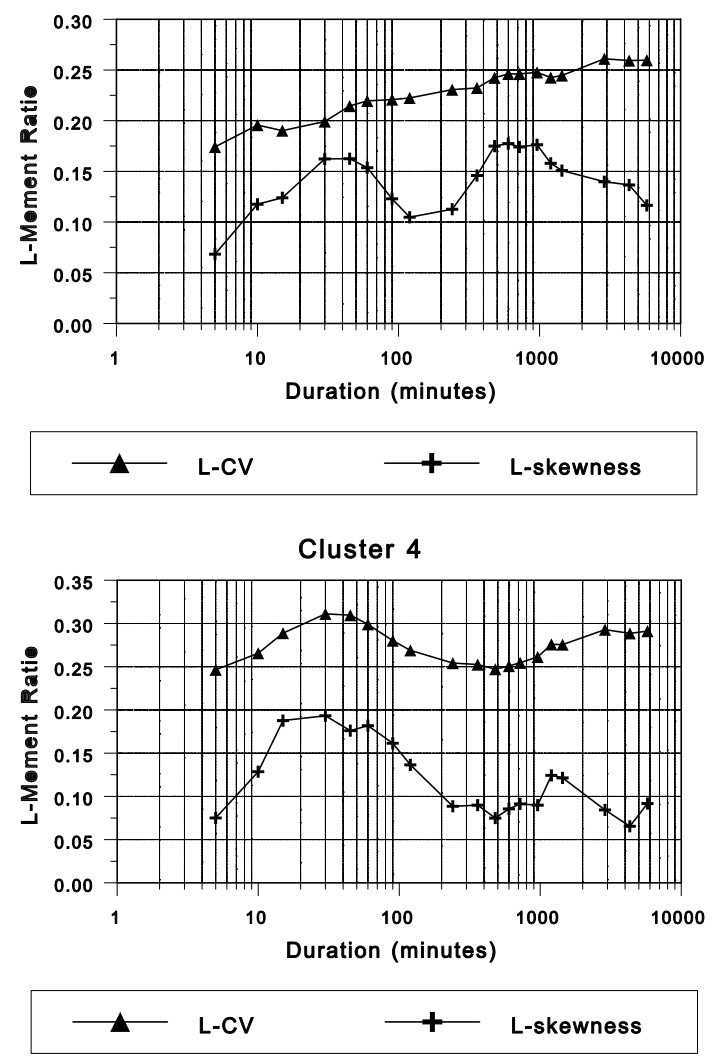

Cluster 5
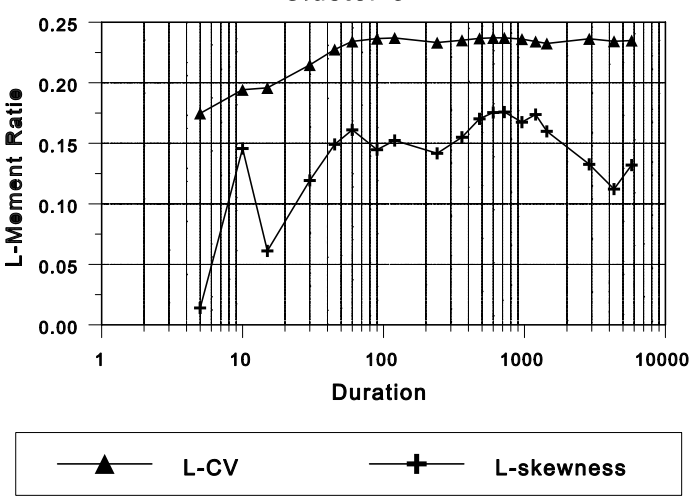

Cluster 8
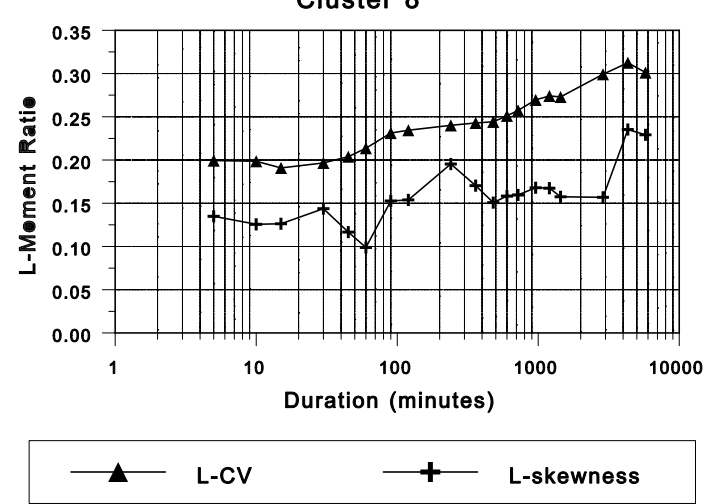

Figure 1

Regional L-moment ratios vs duration for short-duration clusters (Smithers and Schulze, 2003) 

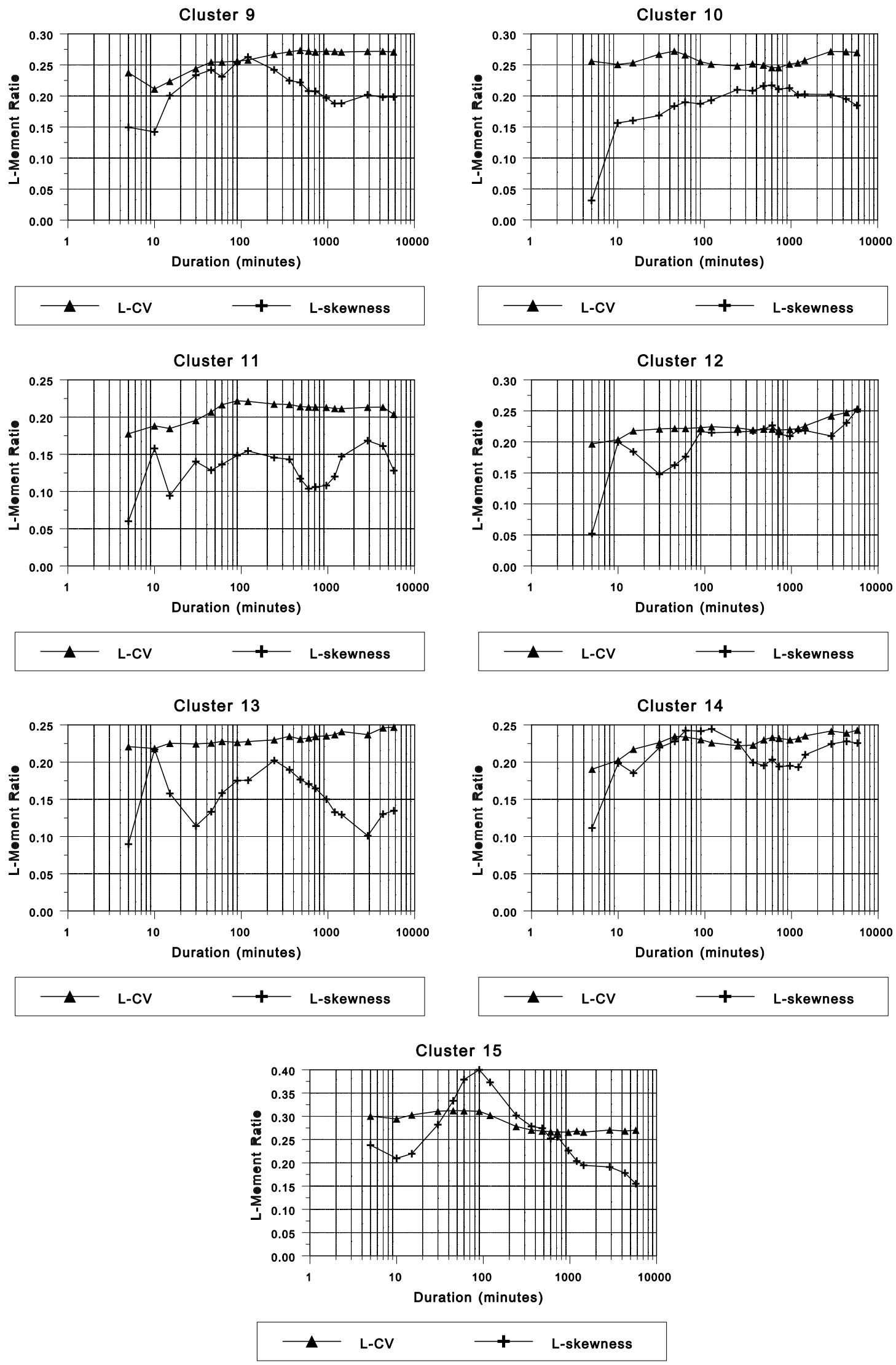

Figure 1 (cont)

Regional L-moment ratios vs. duration for short-duration clusters (Smithers and Schulze, 2003) 
Cluster 2 (Western Cape)
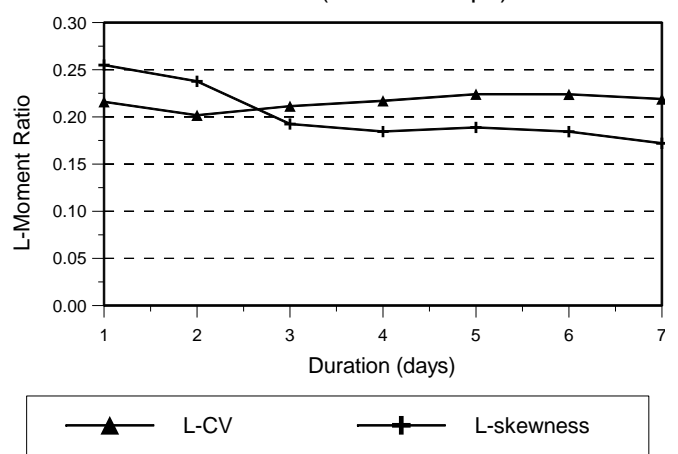

Figure 2

Regional average L-moment ratios vs. durations for selected long duration clusters located in different climate regions of South Africa (Smithers and Schulze, 2003)
Cluster 15 (KwaZulu-Natal)
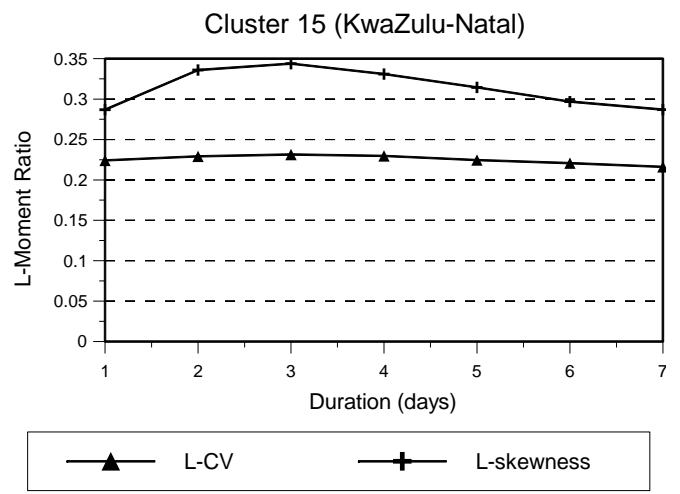

Cluster 24 (Mpumalanga)

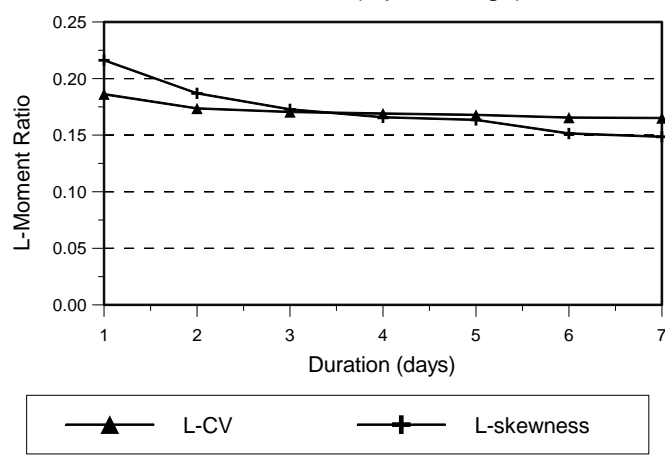

Cluster 60 (Eastern Cape)
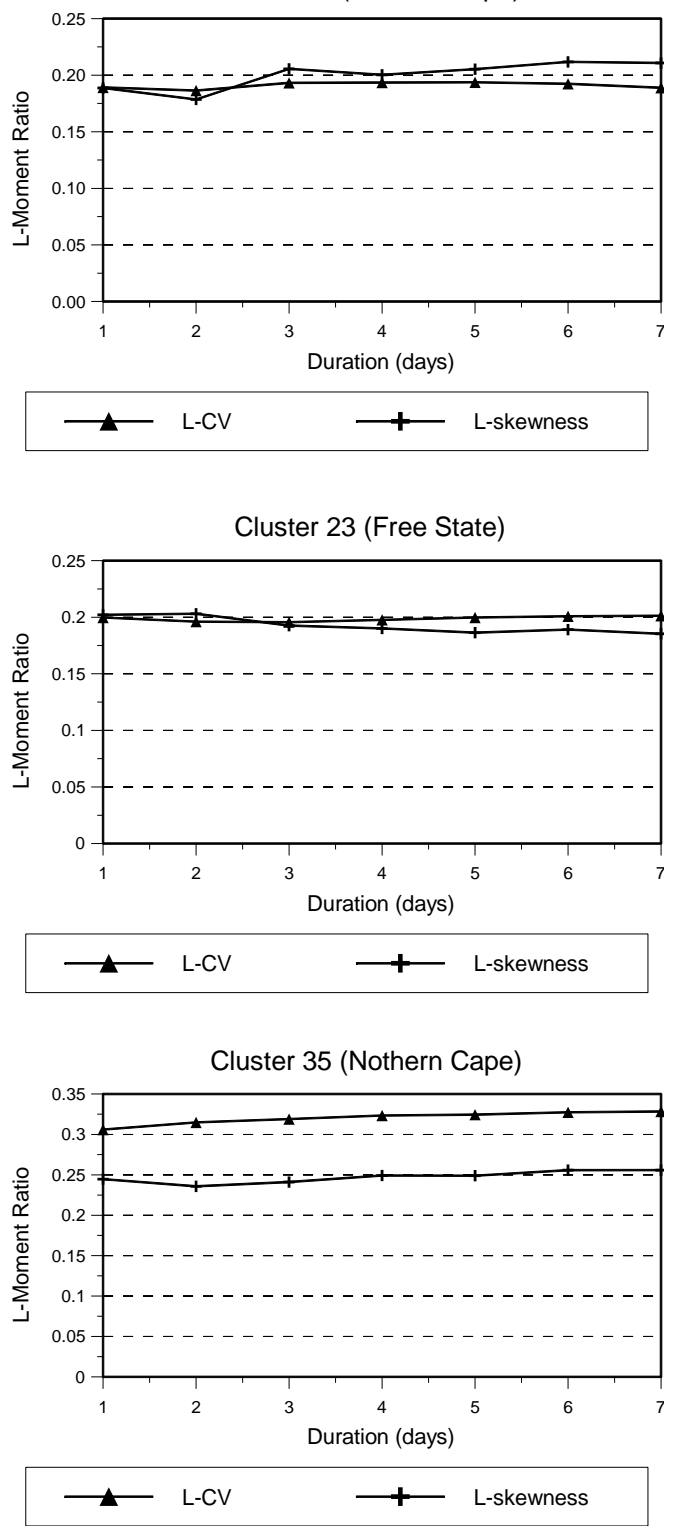
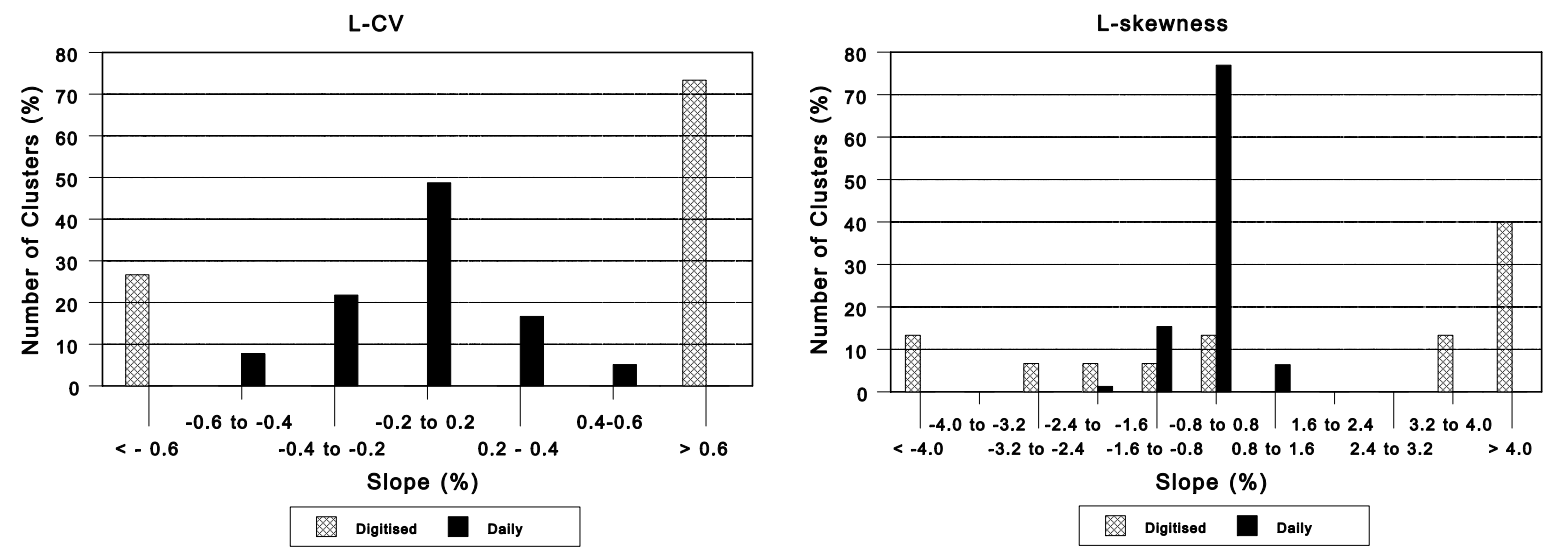

Figure 3

Frequency analysis of the slope of regional average L-moments vs duration computed for short (digitised) and long duration (daily) rainfall clusters (Smithers and Schulze, 2003) 
N23

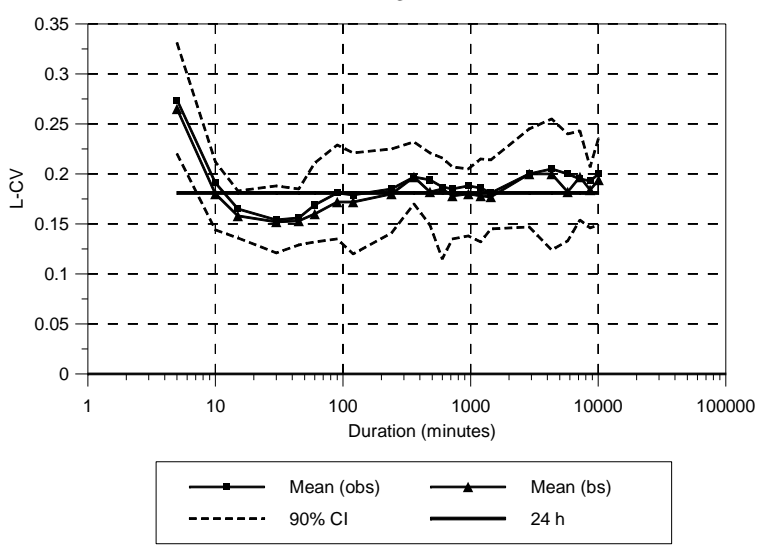

N23: 2 Year Return Period

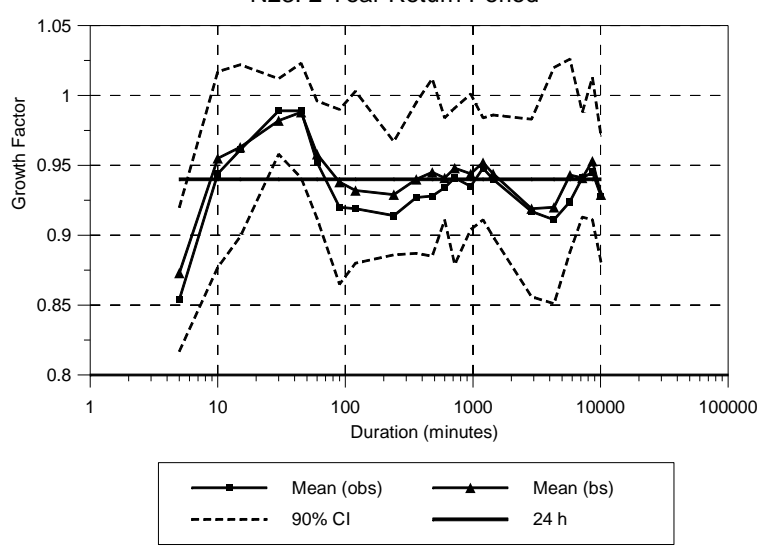

N23

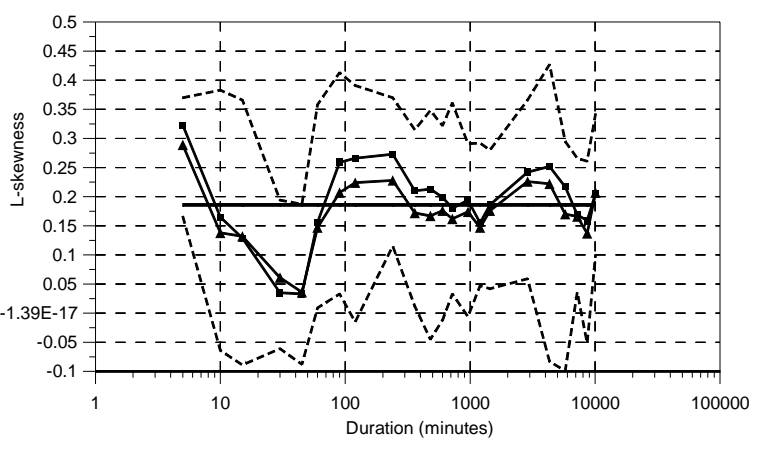

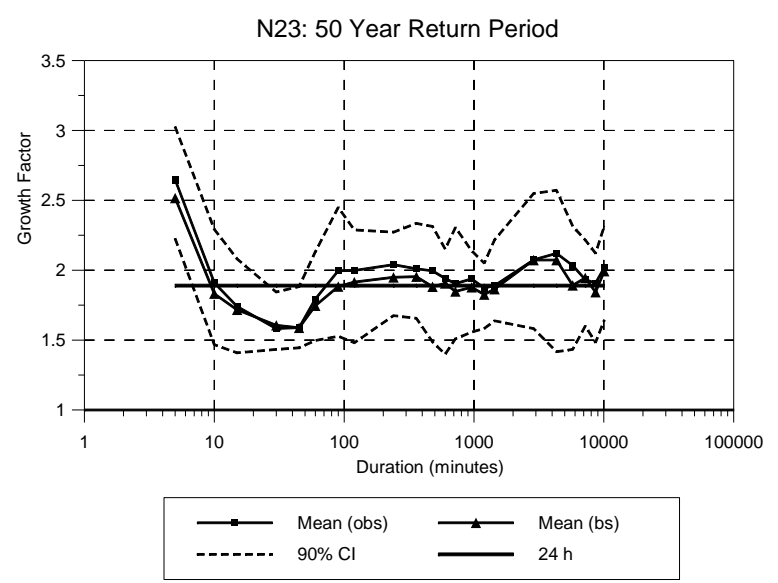

Figure 4

90\% Confidence intervals (Cl) for L-moment ratios (top graphs) and 2 and 50 year return period growth factors (bottom graphs) established from 1000 bootstrapped samples at rain gauge N23 (Ntabamhlope)

Fig. 4. Similar results, with a few exceptions, are shown by Smithers and Schulze (2003) in various climatic regions of South Africa.

Based on the detailed evidence provided by Smithers and Schulze (2003) the following are concluded:

- There are no systematic differences between higher-order Lmoment ratios for annual maximum series extracted using fixed and sliding windows. Hence, the differences in the short- and long- duration growth curves are attributed largely to the different periods and length of record used in the analyses and to a lesser extent to the errors in the digitised rainfall data.

- It is evident that there is considerable variation with duration in observed higher order L-moments. This is associated with the sampling variability and length and period of record.

- The most reliable estimates of the L-moment ratios are computed from the daily rainfall data which are more abundant and have longer record lengths than the digitised rainfall data.

- For durations ranging from 30 min to $7 \mathrm{~d}$, the $1 \mathrm{dL}$-moment ratios generally fell within the $90 \%$ confidence intervals computed for each duration from the observed digitised rainfall data using a bootstrapping technique. Similar results, not shown in this paper, were obtained by Smithers and Schulze(2003) using both moving window and stochastic rainfall modelling approaches to estimate the sampling variability.
It is thus concluded that the $1 \mathrm{~d} \mathrm{~L}$-moment ratios, and hence growth curves, are the most reliable estimate of the L-moment ratios for all durations. Design rainfall estimates for all durations may thus be estimated as the product of the $1 \mathrm{~d}$ growth curves and an estimate of the mean of the annual maximum series (index value) at the site and for the duration in question. The methodology developed for estimating the mean of the annual maximum series at un-gauged locations in South Africa is summarised in the following section.

\section{Estimation of the mean of the annual maximum series at un-gauged locations in South Africa}

The methodology developed by Smithers and Schulze (2003) for estimating the mean of the annual maximum series for all durations at an un-gauged location is dependent on the mean of $1 \mathrm{~d}$ annual maximum series. Using a cluster analysis of site characteristics, the 78 long duration clusters were grouped into 7 regions for the estimation of the mean of the $1 \mathrm{~d}$ annual maximum series. Multiple linear regression relationships with site characteristics (MAP, latitude, altitude) as independent variables enabled the mean of the $1 \mathrm{~d}$ annual maximum series to be estimated at any location in South Africa. Gridded residual errors at stations which had at least 40 years of data were used to correct the estimated values at these sites and ensure that the estimated values were the same as the observed values at these sites. This approach was shown to result in reliable 
and consistent estimates of the $1 \mathrm{~d}$ annual maximum series at sites not used in the analysis.

For durations longer than $1 \mathrm{~d}$, the mean of the $D$ day $(2 \leq D \leq 7)$ duration values were noted to scale linearly as a function of the $1 \mathrm{~d}$ values. The parameters of the regression were found to scale (by a power law relationship) with duration, and three parameters were derived to describe the relationship between the two regression parameters (coefficient and intercept) and duration. Thus, 6 parameters in all were derived for each of the 7 regions which enable the estimation of the mean of the annual maximum series for durations ranging from 2 to $7 \mathrm{~d}$ at any location in South Africa.

For durations shorter than 1 day, the mean of the $H$ minute $(H \leq 1440)$ duration values were found to scale linearly as a function of the $24 \mathrm{~h}$ values. Thus, for each of the 15 short-duration clusters and for 15 durations ranging from 5 to $1200 \mathrm{~min}$, linear regression coefficients were derived.

The approach adopted to estimate the mean of the annual maximum series for any duration is a two-step process. Firstly, the mean of the $1 \mathrm{~d}$ annual maximum series is estimated at the required location using regionalised regressions. Secondly, the mean of the annual maximum series for durations longer than $1 \mathrm{~d}$ are scaled directly from the $1 \mathrm{~d}$ value. For durations shorter than 1 $\mathrm{d}$, the values are scaled from the $24 \mathrm{~h}$ value, which in turn is estimated directly from the $1 \mathrm{~d}$ value for the location. This approach for durations $<24 \mathrm{~h}$ was shown to be more efficient and reliable than the methodology developed by Smithers and Schulze (2000a). The process is illustrated schematically in Fig. 5.

\section{Software developed}

A computer programme with a graphical user interface has been developed in Java to facilitate the estimation of design rainfall depths for any location in South Africa. This software implements the procedures developed by Smithers and Schulze (2003), which are termed the Regional L-Moment Algorithm and Scale Invariance (RLMA\&SI), and enables the estimation of design rainfalls at a spatial resolution of 1 arc minute and for durations ranging from $5 \mathrm{~min}$ to $7 \mathrm{~d}$ and for return periods of 2 to 200 years. The graphical user interface developed is shown in Fig. 6 and typical output from the software is shown in Fig. 7. The software can be

\section{Prediction Interval of the Mean of AMS}

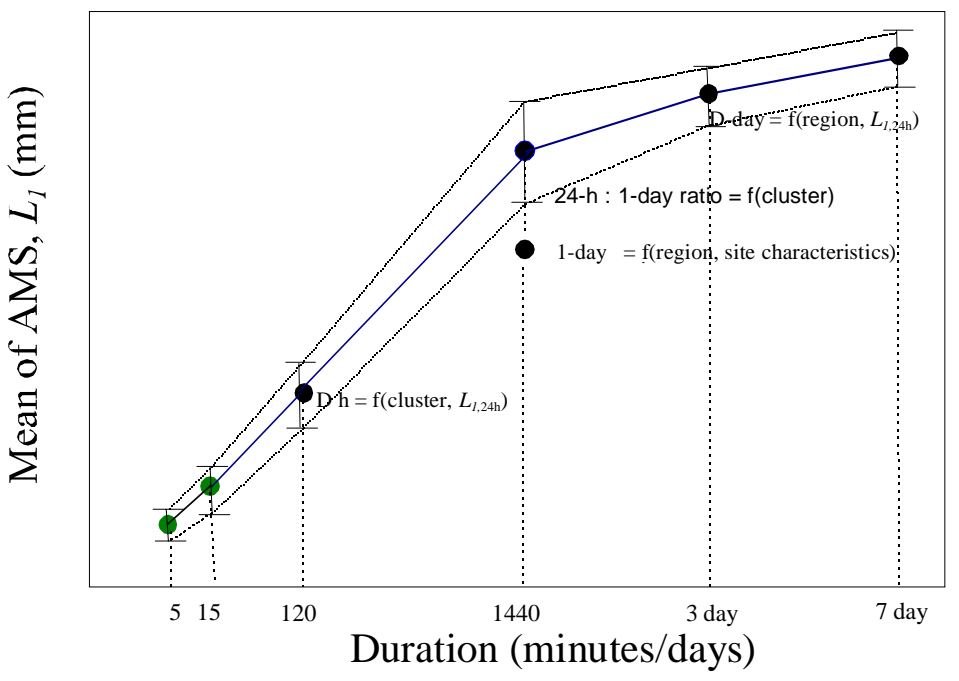

Figure 5

Schematic representation of the estimation of the mean of the annual maximum series (solid line) at un-gauged locations in South Africa. Whisker plots/l-beams and dotted line indicates 90\% confidence interval.
Figure 6

Graphical user interface for the estimation of design rainfall in South Africa

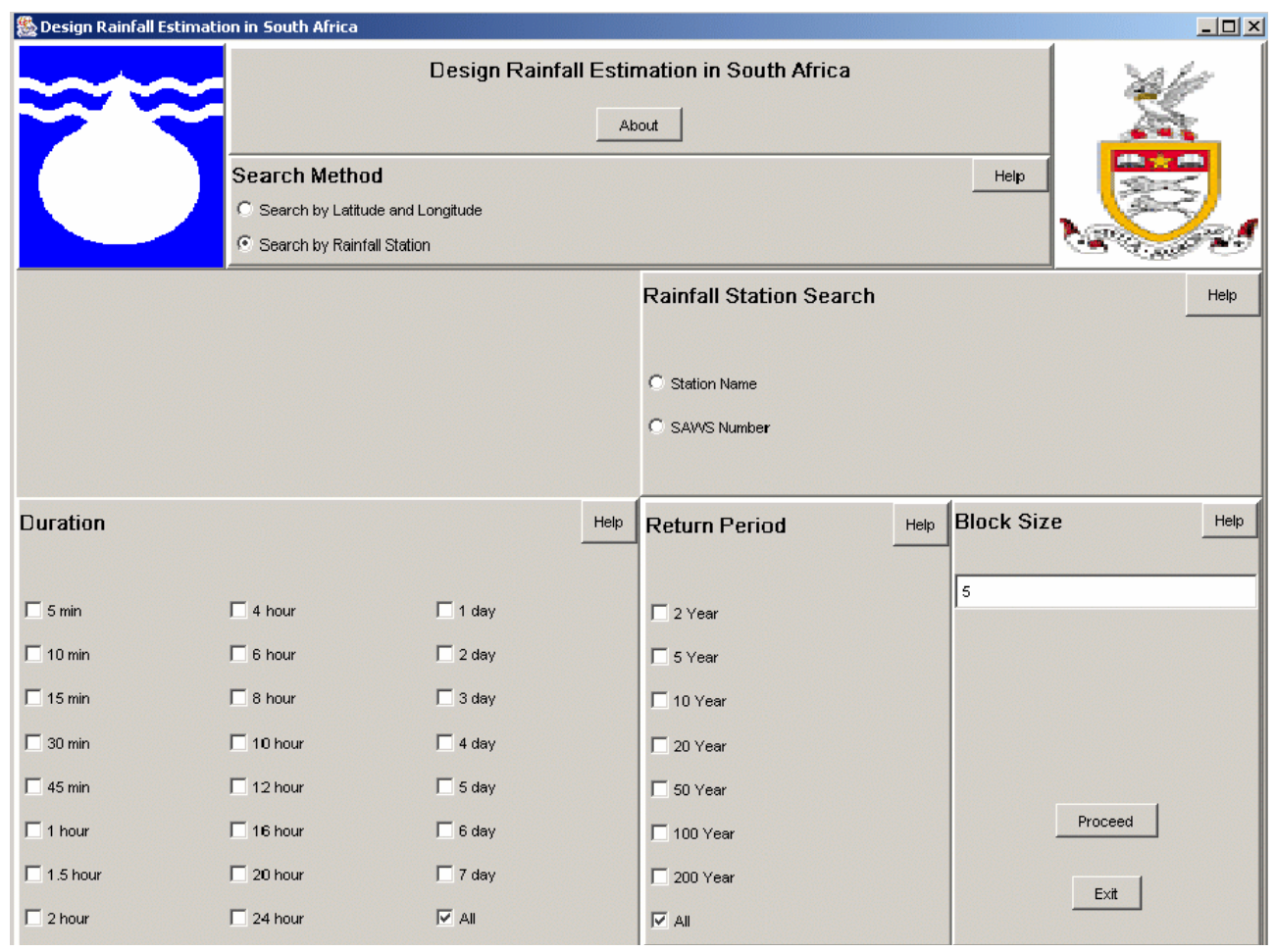




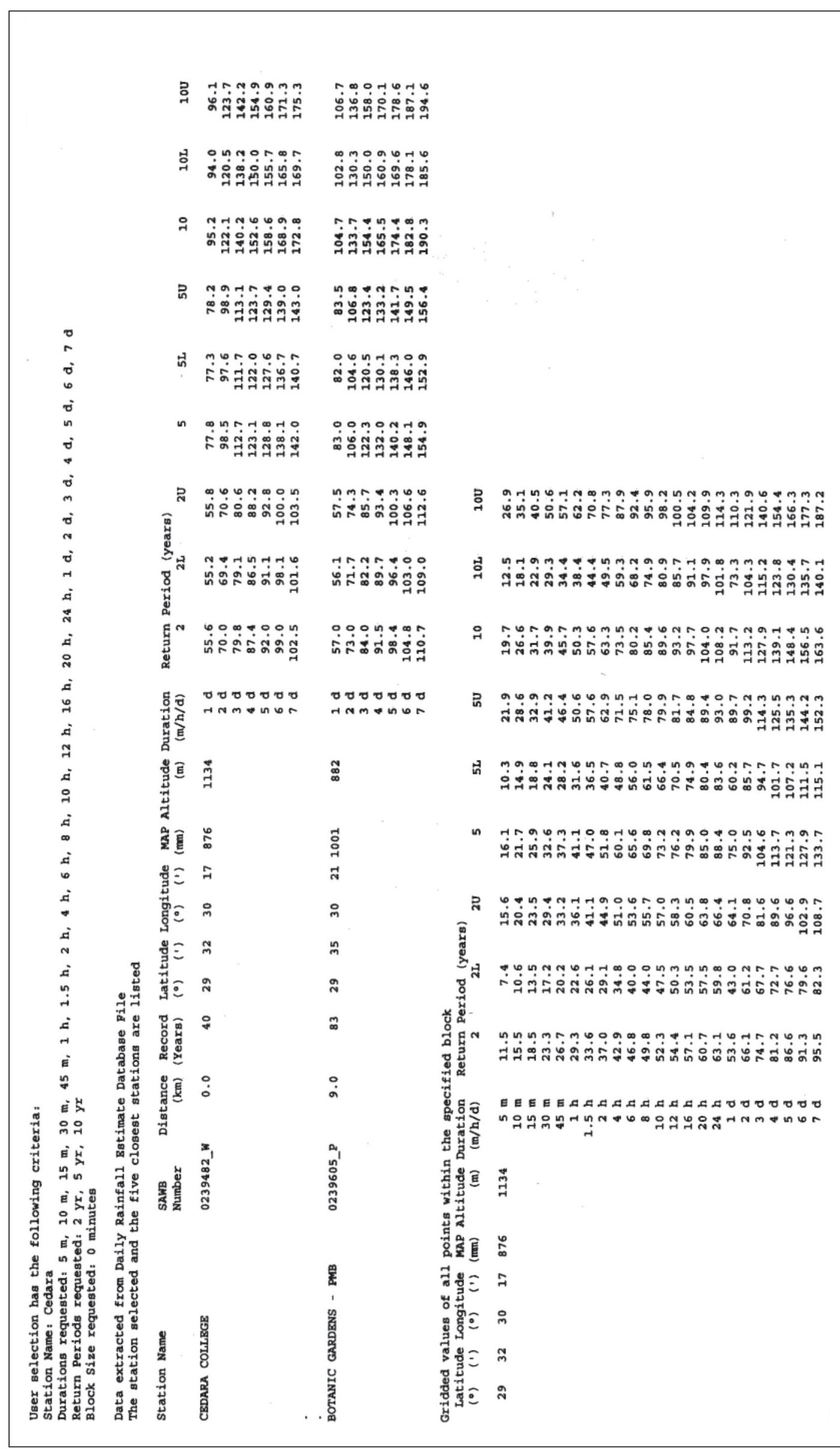

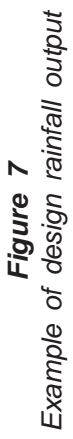


downloaded free of charge from http://www.beeh.unp.ac.za/ HydroRisk/.

\section{Discussion and conclusions}

The estimation of reliable and consistent estimates of design rainfall is an essential element in the efficient design of hydraulic structures. Unlike previous studies which used a single site approach, Smithers and Schulze (2000a; 2000b) developed a regional approach to design rainfall estimation in South Africa. However, much of the focus of the work by Smithers (1998) to estimate design rainfalls for durations $d \leq 24 \mathrm{~h}$ in South Africa was to compensate for the relatively unreliable digitised rainfall data recorded at relatively few stations and which have short record lengths. Hence the RLMA\&SI procedures focus on using the more abundant and reliable daily rainfall data.

The RLMA\&SI procedures developed by Smithers and Schulze (2003) for design rainfall estimation in South Africa, and summarised in this paper, utilises:

- a regional approach;

- growth curves derived from the daily rainfall database, which has far more stations with longer record lengths than those of the digitsed rainfall database;

- the scaling characteristics of extreme rainfall; and

- a regional method which is robust and reliable to estimate the mean of annual maximum series and which is scaled from values estimated from the reliable and abundant daily rainfall data.

In conclusion, the development of the RLMA\&SI procedures by Smithers and Schulze (2003) for design rainfall estimation in South Africa not only adopts a novel approach by utilising the scale invariance of growth curves with duration, but enables reliable and consistent estimates of design rainfall to be made in South Africa by means of a Java-based computer program with a graphical user interface.

\section{Acknowledgements}

The Water Research Commission is gratefully acknowledged for funding the research and development reported in this paper.

\section{References}

ADAMSON PT (1977) Extreme Values and Return Periods for Rainfall in South Africa. Technical Note No. 78. Department of Water Affairs, Pretoria, RSA. 5 pp.

ADAMSON PT (1981) Southern African Storm Rainfall. Technical Report No. TR 102. Department of Water Affairs, Pretoria, RSA.

ADAMSON PT, ZUCCHINI $W$ and ALLEN SJ (1984) On the application of bootstrapping techniques to the assessment of drought risk. In: Maaren $\mathrm{H}$ and Bosman J (eds.). South African National Hydrological Symposium. Technical Report 119, Department of Environment Affairs, South Africa.

ALEXANDER WJR (1978) Depth-Area-Duration-Frequency Properties of Storm Precipitation in South Africa. Technical Report No. TR 83. Department of Water Affairs, Pretoria, RSA.

ALEXANDER WJR (2001) Flood Risk Reduction Measures. University of Pretoria, Pretoria, RSA.

BERGMAN NMC and SMITH AR (1973). A Study of Rainfall Intensities in the Winter Rainfall Area. Report 15/73. Division of Agricultural Engineering Services, Stellenbosch, RSA.

BOBEE B and RASMUSSEN PF (1995) Recent advances in flood frequency analysis. Rev. Geophys. Supplement, July. 1111-1116.

CAMERON DS, BEVEN KJ, TAWN J, BLAZKOVA S and NADEN P (1999) Flood frequency estimation by continuous simulation for a gauged upland catchment (with uncertainty). J. Hydrol. 219 169-187.

CORDERY I and PILGRIM DH (2000) The state of the art of flood prediction. In: Parker DJ (ed.) Floods. Volume II. Routledge, London, UK. 185-197.

HENDERSON-SELLERS A (1980) The spatial and temporal variation of rainfall intensity in South Africa. SA Geograph. 8 (2) 109-112.

HOSKING JRM and WALLIS JR (1993) Some statistics useful in a regional frequency analysis. Water Resour. Res. 29 (2) 271-281.

HOSKING JRM. and WALLIS JR (1997) Regional Frequency Analysis: An Approach Based on L-Moments. Cambridge University Press, Cambridge, UK. 224 pp.

MIDGLEY DC and PITMAN WV (1978) A Depth-Duration-Frequency Diagram for Point Rainfall in Southern Africa. HRU Report 2/78. University of Witwatersrand, Johannesburg, RSA. $57 \mathrm{pp}$.

OP TEN NOORT TH (1983) Flood peak estimation in South Africa. The Civil Engineer in South Africa (October) 557-563.

PEGRAM GGS and ADAMSON PT (1988) Revised risk analysis for extreme storms and floods in Natal/Kwazulu. The Civil Engineer in South Africa (January) 15-20, and discussion (July) 331-336.

PILGRIM DH and CORDERY I (1993) Chapter 9: Flood Runoff. In: Maidment DR (ed.) Handbook of Hydrology. McGraw-Hill, New York, USA.

RAHMAN A, HOANG TMT, WEINMANN PE and LAURENSON EM (1998) Joint Probability Approaches to Design Flood Estimation: A Review. Report 98/8. Cooperative Research Centre for Catchment Hydrology, Monash University, Clayton, Victoria, Australia. 70 pp.

REICH BM (1961) Short duration rainfall intensity in South Africa. SA J. Agric. Sci. 4 (4) 589-614.

REICH BM (1963) Short-duration rainfall-intensity estimates and other design aids for regions of sparse data. J. Hydrol. 1 3-28.

SAWB (1956) Climate of South Africa. Part 3: Maximum 24-Hour Rainfall. SAWB Publication WB 21, Pretoria, RSA.

SAWB (1974) Climate of South Africa. Part 11: Extreme Values of Rainfall, Temperature and Wind for Selected Return Periods. SAWB Publication WB 36, Pretoria, RSA.

SCHULZE RE (1980) Potential Flood Producing Rainfall for Medium and Long Duration in Southern Africa. Report to Water Research Commission, Pretoria, RSA. 37 pp.

SCHULZE RE (1984) Depth-duration-frequency studies in Natal based on digitised data. In: Maaren $\mathrm{H}$ (ed.) South African National Hydrology Symposium. Department of Environment Affairs. Technical Report TR119. Pretoria, RSA. 214-235.

SINSKE BH (1982) Bepaling van uiterste neërslag vir intermediëre reënvalduurtes in Suidelike Afrika. Water SA 8 (3) 149-154.

SMITHERS JC (1993) The effect on design rainfall estimates of errors in the digitised rainfall database. In: Lorentz SA, Kienzle SW and Dent MC (eds.) Proc. $6^{\text {th }}$ South African National Hydrological Symposium. Department of Agricultural Engineering, University of Natal. Pietermaritzburg, RSA. 95-102.

SMITHERS JC (1996) Short-duration rainfall frequency model selection in Southern Africa. Water SA 22 (3) 211-217.

SMITHERS JC (1998) Development and Evaluation of Techniques for Estimating Short Duration Design Rainfall in South Africa. Unpublished Ph.D. dissertation, University of Natal, Pietermaritzburg, South Africa. 356 pp.

SMITHERS JC and SCHULZE RE (2000a) Development and Evaluation of Techniques for Estimating Short Duration Design Rainfall in South Africa. WRC Report No. 681/1/00. Water Research Commission, Pretoria, RSA. 356 pp.

SMITHERS JC and SCHULZE RE (2000b) Long Duration Design Rainfall Estimates for South Africa. WRC Report No. 811/1/00. Water Research Commission, Pretoria, RSA. 69 pp.

SMITHERS JC and SCHULZE RE (2003) Design Rainfall and Flood Estimation in South Africa. WRC Report No. 1060/01/03. Water Research Commission, Pretoria, RSA. 155 pp.

VAN HEERDEN WM (1978) Standaard intensiteitkrommes vir reënval van kort duurtes. The Civil Engineer in South Africa (October) 261-268. 
VORSTER JA (1945) Ingenieursprobleme by gronderosiebestryding. Bulletin No. 259. Department of Agriculture, Pretoria, RSA.

WEDDEPOHL JP (1988) Design Rainfall Distributions for Southern Africa. Unpublished M.Sc. Dissertation, Department of Agricultural Engineering, University of Natal, Pietermaritzburg, RSA.

WEDDEPOHL JP, SCHULZE RE and SCHMIDT EJ (1987) Design rainfall time distributions based on digitized data. In: Hughes DA and Stone A (eds.) Proc. $3^{\text {rd }}$ South African National Hydrological Symposium. SANCIAHS, Pretoria, RSA. 577-597.

WOOLLEY LC (1947) Rainfall intensity duration curves and their application to South Africa. Minutes of Proceedings, Third Meeting. SAICE. Cape Town, RSA. 115-153.

ZUCCHINI W and ADAMSON PT (1989) Bootstrap confidence intervals for design storms from exceedence series. Hydrol. Sci. J. 34 (1) $41-48$ 